\title{
Partnering for sustainability in agri-food supply chains: the case of Barilla Sustainable Farming in the Po Valley
}

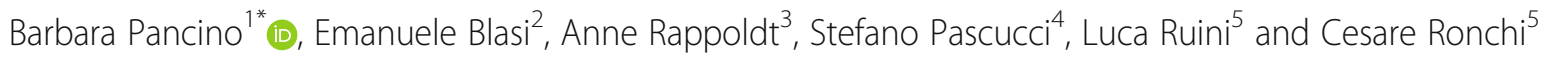

\author{
* Correspondence: bpancino@ \\ unitus.it \\ ${ }^{1}$ Department of Economics \& \\ Management (DEIM), Università \\ degli Studi della Tuscia, Via del \\ Paradiso 47, 01100 Viterbo, Italy \\ Full list of author information is \\ available at the end of the article
}

\begin{abstract}
The objective of the paper is to understand the process of designing a multistakeholder partnership in the adoption of sustainable innovations in value chains. More specifically, the focus is on the design of feasible types of horizontal agreements and contractual formulas to be implemented in the agri-food supply chain in order to introduce sustainable agricultural practices. To this purpose, the Barilla Sustainable Farming initiative, which is currently in the first phase of designing an MSP, is used as a case study.
\end{abstract}

Keywords: Supply chain protocols, Sustainability, Crop rotation, Horizontal agreements, Contract design

\section{Introduction}

Complex and urgent sustainability issues are caused by interaction of a number of variables that impact efficiency and sustainability of local agriculture. First, there is a decrease in the amount of arable land available as a result of urbanization, salinization, desertification, and environmental degradation (Ronald 2011). Other variables are climate change (Kesavan 2015), eating habits, (BCFN 2011), increases in food prices and fuel costs, pesticide pollution, and pest adaptation and resistance (Lichtfouse et al. 2009). Moreover, the agricultural activities of the last 50 years have been focussed on maximizing productivity through the adoption of new technologies and modernization of production techniques, such as high-yielding plant varieties, practice of monoculture, and mechanization and use of agrochemicals (BCFN 2011; Bernstein 2014; Stewart et al. 2014). On the one hand, these activities resulted in a period of high productivity repeatedly associated with low food prices and, on the other hand, also in intensive and often irreversible exploitation of the natural resources as an effect of soil erosion and decreased fertility, water contamination, deforestation, and loss of biodiversity (BCFN 2011; Kesavan 2015; Lichtfouse et al. 2009).

Within this context, as Aiking and De Boer (2004) argue that only a few corporations are in charge of the food production system; thus, multinationals should hand over some form of control to stimulate democratic multi-level governance to make food production more sustainable. For instance, they can be promoters of the so-called multi-stakeholder partnerships.

(c) The Author(s). 2019 Open Access This article is distributed under the terms of the Creative Commons Attribution 4.0 International License (http://creativecommons.org/licenses/by/4.0/), which permits unrestricted use, distribution, and reproduction in any medium, provided you give appropriate credit to the original author(s) and the source, provide a link to the Creative Commons license, and indicate if changes were made. 
'Multi-stakeholder partnership' (MSP) is an overarching concept which highlights the idea that different groups can share a common problem or aspiration, while nonetheless having different interests or 'stakes"' (Brouwer et al. 2015).

MSPs range from short consultation processes to multi-year arrangements that may evolve through many phases. Some MSPs are extremely systematized and financed by formal actions, while others are much more specific and simple. Different groups will take the lead in initiating MSPs, but the common key element seems to be the motivations. Partnership motivations are the existence of assumptions of risks (Johnston and Gudergan 2007; Roehrich et al. 2014) or strategic issues, such as assessment of opportunities and threats and use of own strengths to decrease them (Dentoni et al. 2012). Another relevant element in shaping a MSP is the organizational and human resources and capabilities (Dentoni et al. 2012). In addition, Hartwich et al. (2008) argue that the objective or common interest of the different stakeholders is a determinant of how the partnership is formed (Hartwich et al. 2008). In order to have successful partnerships, there are some basic and simple preconditions that should be taken into account. First, a successful partnership requires overlapping agendas and motivations between all the involved stakeholders (Heldeweg et al. 2015). Moreover, trust is an important element, which is based on past experiences or previous relations between the stakeholders (Glasbergen et al. 2007). In addition, the allocation of responsibility and authority is needed (De Schepper et al. 2014) by a contractual agreement, for example (Glasbergen et al. 2007).

Partnerships also imply a new form of governance (Backstrand 2006). The literature illustrates a wide spectrum of governance structures for MSPs. It can vary by several different characteristics. For instance, Waring et al. (2013) differentiate between tight and loose partnerships, where tight arrangements refer to horizontal resource sharing and collaboration, and loose arrangements include vertical contracting between a public purchaser and a private provider. Tight/loose differentiation is made based on characteristics of financing and risk sharing, collaboration in strategic planning and design, and level of resource sharing. Waring et al. (2013) also explore the relationship between "upstream" tight or loose arrangements and "downstream" service and workforce management. Furthermore, Keast et al. (2007) define three forms of horizontal integration modes for policy and service in a level of integration continuum: cooperation, coordination, and collaboration. Cooperation is conceptualized as a starting point of interorganizational relationships and is characterized by small efforts and low levels of relationship intensity, while organizations remain independent and autonomous. It involves low risk because no changes are required in existing practices. Organizations take into account each other's goals, and relations are short term and informal. Coordination is found in the middle of the continuum-between cooperation and collaboration-and implicates that there is a shared goal between the partners and they work together according to more structured mechanisms than in case of cooperation. Although there is a shared goal, there is no loss of individual autonomy of the different partners. The partnerships focus on the fulfilment of tasks or activities that are managed to drive a specific outcome (Keast et al. 2007). In addition to information sharing, it requires joint planning and possible joint funding. Increase of effort and commitment can lead to 
growing shared benefits and shared risks. Collaboration is the ideal type found at the other side of the spectrum and goes beyond the instrumental process of joint task fulfilment. Collaboration deals with high intensive relationships, connections, and resources; thus, even boundaries between agencies can become blurred. Collaboration is characterized by shared goals and goal setting, high level of commitment and contribution, and high level of trust. In addition to the joint instrumental approach that is associated with coordination, also new forms of engagement, structures, and processes are developed over time. Moreover, collaboration has the potential to achieve greater efficiencies of scale and outcomes than cooperation and coordination, but it is difficult to develop and to sustain. This integration form also involves the highest degree of risk. Therefore, coordination is often considered safer, requires less time to establish, and lies within the comfort zone. The three integration modes differ in the level of connection and intensity. Keast et al. (2007) argue that the '3C" are complementary and not competitive; they are the key to select the right mix.

Moreover, multinationals are in business to make profits, so they will barely participate in sustainability practices if there is a 'win-win' situation-meaning that there is a business advantage in addition to the social and environmental advantages (Rondinelli and Berry 2000). An example of this type of 'win-win' process is the Barilla Sustainable Farming (BSF) initiative, which is carried out by the Barilla Group (Blasi et al. 2015). Indeed, in 2013, Barilla introduced a sustainable agriculture practice by establishing horizontal agreements between three of its main input suppliers: Co.Pro.B. for sugar beet, Cereal Docks for oilseeds, and Casalasco Tomato Consortium for tomato (BCFN 2015). The agreement entails that the supply chains become integrated by means of a crop rotation system with the wheat crops, sugar beet, rapeseed, and sunflower (Barilla 2014). Currently, these horizontal agreements are bilateral, which means that the Barilla Group has a specific agreement with each one of the supplier. The idea is to step forward passing from bilateral agreements to a multilateral one.

The objective of the paper is, indeed, to understand the process of designing a multistakeholder partnership (MSP) in the adoption of sustainable innovations in value chains, like the one of defining feasible types of horizontal agreements and contractual formulas to be implemented in the agri-food supply chain in order to introduce sustainable agricultural practices. The BSF initiative, which represents a perfect case study for this purpose, is currently in the first phase of designing an MSP; therefore, the initiating phase will be the main focus of the analysis. The results will then permit to identify the main features necessary to make the shift from an agreement to a proper contract, which has already been pointed out as the main critical point for a wider implementation of these type of agreements (Pancino et al. 2015).

\section{Method}

\section{Research strategy and case study}

This research aims to understand the process of designing a multi-stakeholder partnership in the adoption and diffusion of sustainable innovations in food value chains, promoted and facilitated by private actors. The theoretical framework developed in the literature study in the previous section forms the basis for the empirical analysis. The BSF initiative is currently in the first phase of designing an MSP; therefore, the initiating phase will be 
the main focus of the empirical analysis. The governance structures are established in the third phase of the design process, so this research will only reflect on the rationales that are found during the initiating phase.

A schematic representation of Barilla with its suppliers and the other stakeholders involved in the BSF initiative is schematized in Fig. 1. Horizontal agreements, or supplier-supplier relations, extend the concept of a supply chain towards a supply network (Johnsen et al., 2008; Lamming et al., 2000, cited in Wilhelm 2011), where supply chains are seen as "connected strings of organizations involved in the production and supply of a particular product or product family" (Johnsen et al., 2008; cited in Wilhelm 2011, p. 664). Supplier-supplier relationships within a supply network can be competitive, or cooperative, or there is the possibility of lack of ties. In these relations, cooperation and competition can exist next to each other, but one is likely to be stronger (Wilhelm 2011). Co.Pro.B., Cereal Docks, and Casalasco Tomato Consortium are suppliers with cooperative ties since they provide Barilla with different crops. The aim of the horizontal agreement is to facilitate farmers in engaging a multi-year crop rotation system which will lead to new market opportunities deriving from the different value chains involved. In the analysed case, tomato, durum wheat, and oilseed crops (sunflower, maize, or sorghum) are consciously rotated to improve soil fertility as well as to reduce the input amount per land unit. In this path, the nitrogen fixer crops play a critical role, where these are not feasible with the structural and pedo-climatic features of the farms within the macro-region investigated.

\section{Data collection}

This research consisted of three phases of data collection: documentation, interviews, and participant observations. Documentation and interviews were part of the diagnostic stage, and the participant observation during a design exercise with the stakeholders was part of the therapeutic stage of the research, which involves collaborative change experiments (Baskerville 1997).

First, scientific articles and company documents were sources for the documentation. For the literature study, scientific articles and books were used. In addition, company documents were used for the case description. The theoretical framework that is developed in the literature study formed the basis for the empirical analysis and the interview questions.

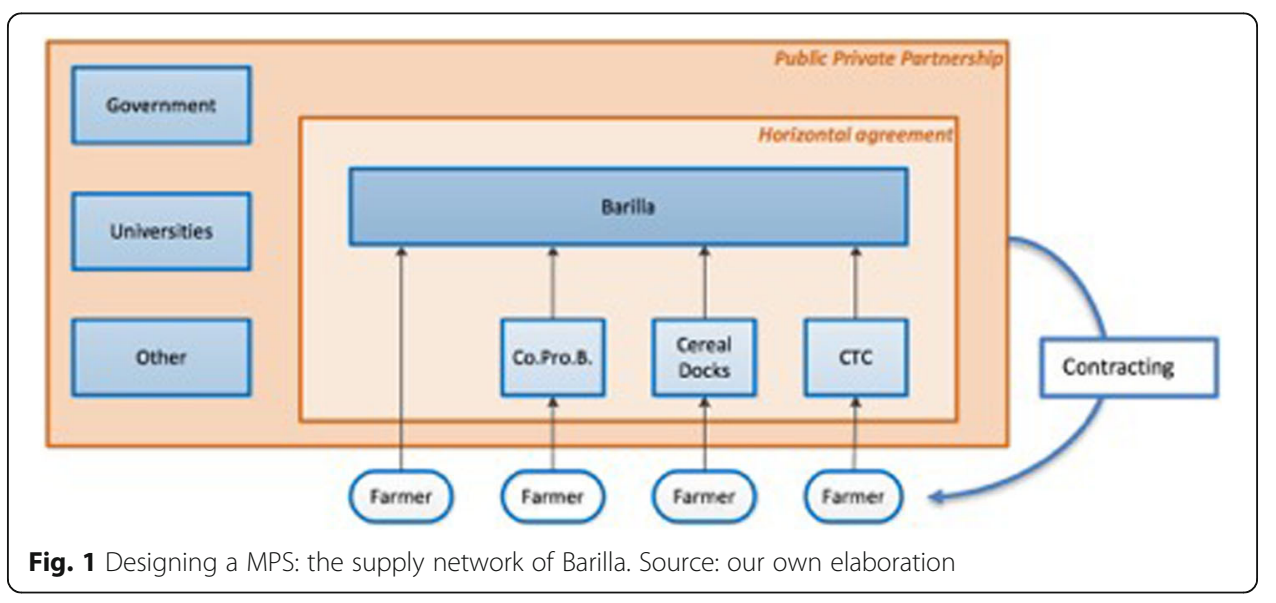


Then, in February 2016, four interviews were conducted with representatives from the organizations Barilla, Casalasco, Co.Pro.B., and Cereal Docks. The choice of interviewing sub-supplier like elevators, cooperatives, and PO instead of farmers is due to the greater bargaining power they have in favouring the contract signature by their associated farmers. The interviews were semi-structured and consisted of open questions. A standardized interview protocol was designed, but probes and follow-up question were used. Each interviewee was granted permission to make an audio recording of the interview, and also, the transcripts were checked and validated by the interviewees. The interviews took approximately $45 \mathrm{~min}$ and were recorded, transcribed, and analysed. The interviewees were selected because they represent the organizations that are involved in the BSF initiative.

The empirical analysis of this research focused on the initiating phase of designing a MSP, because this is most relevant for the BSF initiative. The interviews provided a first understanding of the current situation and therefore focused on the first three steps of the initiating phase: clarify reasons, initial situation analysis, and mobilize champions.

The first part consisted the introduction in which the researcher explains the context of the research and the goal of the interview. In addition, the structure and the expected duration of the interview were explained and the interviewee was asked permission to make an audio recording of the interview.

The second part of the interview aimed to undertake an analysis of the current situation of the BSF initiative to understand the context of the initiative in terms of processes, involvement, motivations, interests, and expectations of the different stakeholders.

Questions for analysis of the current situation of an inter-organizational collaboration targeted for example roles of the different stakeholders, contributions, relationships, and reasons for collaboration (Butterfield et al. 2004).

The third part of the interview aimed to understand preferences for structuring or organizing the collaboration. Therefore, the questions in the second part targeted preferences about how to collaborate and in terms of management, structure, and coordination mechanisms.

Finally, the last sections contained a final statement which is offered to the interviewee in which two options were presented: (1) to establish a multi-stakeholder partnership or (2) to directly design a contract for the crop rotation system based on the existing horizontal agreements. Here, the attitude of the stakeholders towards collaboration in an MSP was analysed.

After the interviews, a multi-stakeholder meeting was organized in Parma (Italy) on the 8th of March 2016. During this meeting, the first findings of the interviews were presented followed by an open discussion. Attendants of the meetings were representatives from Barilla, Casalasco, Co.Pro.B., Tuscia University of Viterbo, and Wageningen University. The multi-stakeholder meeting contained an experimental design exercise with the stakeholders involved in the BSF initiative to take action in the first steps for designing the MSP and negotiate the first pilot contracts.

The design exercise was built upon the information gathered during the literature study and the interviews and consists of an experimental design exercise during a multi-stakeholder meeting. During the design exercise, the findings of the literature study and the interviews were presented, followed by an open discussion to confirm or complement the findings. Moreover, the design exercise focused on the next steps of 
the initiating phase: establish an interim steering body, build stakeholder support, establish scope and mandate, and outline the process.

\section{Results and discussion}

The interview round focused on the analysis of the first three steps of the initiating phase as presented in the theoretical framework: clarify reasons, initial situation analysis, and mobilization of champions. The attitude of the stakeholder towards a MSP in general was also included by asking for preference for the option to design a MSP or to develop contracts based on the existing horizontal agreements.

The shared objective of the BSF initiative mentioned during the interviews is well aligned among the different stakeholders. The objective can be defined as a long-term program of 4 or 5 years for stabilization of prices and stabilization of the market. Stabilization is seen as a win-win situation for both farmers and manufacturers. First, the farmers will face less volatile prices in the market and engaging in the rotation system ensures outlet to the crops that they produce. For the industry, it involves an increase in quality and sustainability—such as Good Agricultural Practices (GAP)—standards.

There are more benefits of the rotation system pointed out by the stakeholders. First, production becomes more efficient. Better quality and fertility of the soil require less input leading to lower production costs and improved quality of the products, and therefore an increase in competitiveness. Moreover, less volatility in the market reduces the economic risks for both the farmers and the manufacturers. This win-win situation only provides security for long-term production, because it provides on the one hand a stable income and on the other hand a stable supply. Stabilization means a change of the total free market system, but aims to find a right compromise in between a free market and a protected market. Moreover, conflicting interest can cause problems because the stakeholders that are involved in this collaboration are indirect competitors. Even negotiation of prices in a contract with multiple stakeholders is a conflict of interest per definition. Quality, quantity, timing, and price must all be negotiated.

The existing relationships between the different stakeholders can be described as follows. First, Barilla is in the centre of the collaboration. Barilla has strong ties with Casalasco and Co.Pro.B. since they are already existing suppliers of Barilla, and is only starting a relationship with Cereal Docks in this rotation initiative. However, between Casalasco, Co.Pro.B., and Cereal Docks, there are no current or existing linkages.

Barilla can thus be seen as the institutional entrepreneur, thus an agent who mobilize own resources to create institutions (Pacheco et al. 2010), that facilitates and takes the lead in changing the institutional environment.

The involvement of the public party that is foreseen by the four partners is first for providing funding and support. Furthermore, the local administration will guarantee that all parties respect the contract, as this will be legally binding. Inter-organizational collaboration in a MSP involves maximization of resources and expertise. All four companies have knowledge and experience in crop rotation, and existing relationships with universities and agronomists make a good understanding of agronomic practices of rotation. Indeed, the involvement of research institutes and local public authorities in the partnership contributes to the creation of a learning network, and the legitimacy of the initiative can help to facilitate the adoption of changing practices through support and embedding within existing regulatory frameworks. To this regard, it is important to note that in all the 
regions where the four companies provide their raw materials, rural development programs defines agro-climate-environmental measures (measure 10) where crop rotation schemes are included as a mandatory requirement of integrated pest management schemes. In this case, the farmers can voluntary apply to these pluriannual schemes and receive per hectare subsides by the CAP second pillar budget.

The win-win process is then guaranteed. First, the farmers will face less volatile prices in the market and engaging in the rotation system ensures outlet to the crops that they produce, as well as comply with public subsided schemes. For the industry, it involves an increase in quality and sustainability-such as Good Agricultural Practices (GAP)—standards. There is an increased demand from large clients such as processors, wholesalers, and retailers for GAP manners and sustainability practices in agricultural production. Alignment of the objectives between the stakeholders is a strength of this collaboration.

The tool to reach the objective is to design contracts for the farmers. At the moment, the four partners share horizontal agreements, thus a 'mutual interest in supporting specific activities'. However, the existing horizontal agreement is not binding and entails that the four stakeholders Barilla, Casalasco, Co.Pro.B., and Cereal Docks have their own program in sustainable production. To integrate and align these different programs into a crop rotation system is going to be the challenge. To do so, the horizontal agreement is not sufficient and it is needed to establish a contract, which is explained as 'something that obliges you to respect the conditions'. A contract is more specific and includes that a certain amount of a crop will be purchased by the organization and, on the other side, that the farmer commits himself to produce a certain amount.

Thus, the key is to base the Sustainable Farming Initiative on a two-level approach: the protocol level, which defines the agreement among the industrial partnership, and the contract level that defines the terms to be respected between suppliers and purchasers.

In order to define a general protocol, which defines the terms of the agreement, we firstly examined the different cultural practices, production regulations, and monitoring and control systems already implemented by the four partners. The analysis has permitted the identification of the actual grade of compatibility between the single systems and the consequent draft of the general aspects to be included in the protocol. These are the commitments to the conversion of rotation practices, a common disciplinary of production, coordination of procurement, information sharing and communication, and coordination of the stakeholders involved in the different locations at a horizontal level. The protocol has been then sharped through a series of meetings, interviews, and exchange of information and with the industrial partners involved.

Based on the general aspects specified in the protocol, a series of supply contracts to be submitted to the evaluation of farmers participating in the project has been shaped. The elements of the contracts, which aims at engaging farmers in implanting crop rotations, are price, quantity, amount of land, number of years, options, and locations. However, it is not possible to design a single standard contract to offer to the farmers to determine how the output is shared for multiple locations. The specific contract terms must be therefore defined, within the general protocol, but in accordance with the specific rotations and locations. The submission of a set of potential contracts to a sample of farmers potentially interested in experiencing the contract and the introduction of the rotation is the objective of the third phase of the project. 
In this path, considering the greening crop diversification commitments and CAP reform (European Commission 2018), where crop rotation is proposed to be linked to the direct payments, MSP could be useful to increase farmers capabilities to accomplish the new CAP regulatory framework and connect direct payments distributions. The member states will probably account in the climate and environmental eco-schemes (Art. 18, COM (2018)392) and more ambitious environmental practices, as well as crop rotation that include nitrogen fixer crops or green manure crops in arable land management. At the same time, further contracts will be used to improve data collection about suitable crop rotation implementation, supporting public monitoring activities and CAP impact evaluations.

\section{Conclusions}

The multi-stakeholder partnership seems to be the answer for implementing sustainable innovations in value chains. From our research, it emerges that it is not possible to design a single standard contract that also includes variation for different locations or division of output between the stakeholders. Moreover, besides engagement of the farmers, the stakeholders must also be committed and other requirements such as information sharing, communication, and evaluation are important requirements to establish the rotation system which is the objective of the multi-stakeholder partnership.

Thus, to implement the crop rotation system proposed in the case study, a two-level approach is suggested. The first level is the contract, which aims to engage the farmers and exists of specifics for the rotation practices such as price, quantity, quality, amount of land, number of years, and locations. A set of contracts is required for the rotation system because it is not possible for one contract to include all elements. The set of contracts could, for instance, consist of contracts between the cooperatives and the farmers.

The second level, instead, refers to the partnership and contains specifics for collaboration between the stakeholders in the partnership, such as the conversion of rotation practices, coordination of procurement, and coordination of stakeholders at a horizontal level. This level is required to integrate the supply chains and targets the engagement of the partners and collaboration between them, which is required to develop a set of contracts that can be offered to the farmers. The aim of this level is to develop a set of contracts, the engagement of partners, and the management of different contracts for different locations.

\section{Acknowledgements}

This paper has been selected as a best paper of the 53rd SIDEA Conference in San Michele all'Adige and Bolzano (2224 September 2016). It has been accepted for publication in this journal following the usual revision process.

\section{Authors' contributions}

BP contributed to write introduction, results and discussion, conclusions. EB contributed to write method:research strategy and case study, results and discussion, conclusions. AR contributed to write introduction, method: data collection. SP contributed to write method: research strategy and case study, conclusions. LR contributed to write method: research strategy and case study. CR contributed to write method: data collection. All authors read and approved the final manuscript.

Funding

This work is supported by the H2020 project Diverfarming - Grant Agreement 728003.

Availability of data and materials

Not applicable

Competing interests

The authors declare that they have no competing interests. 


\section{Author details}

${ }^{1}$ Department of Economics \& Management (DEIM), Università degli Studi della Tuscia, Via del Paradiso 47, 01100 Viterbo, Italy. ${ }^{2}$ Department for Innovation in Biological, Agro-food and Forest systems (DIBAF), Università degli Studi della Tuscia, Via S. Camillo de Lellis snc, 01100 Viterbo, Italy. ${ }^{3}$ Wageningen University, Hollandseweg 1, 6707 KN Wageningen, The Netherlands. ${ }^{4}$ University of Exeter Business School, Penryn Campus, G16 The SERSF Building, Cornwall, UK. ${ }^{5}$ Barilla G\&R Fratelli SPA, via Mantova 166, 43122 Parma, Italy.

Received: 8 October 2018 Accepted: 11 June 2019

Published online: 14 July 2019

\section{References}

Aiking H, De Boer J (2004) Food sustainability: diverging interpretations. Br Food J 106(5):359-365

Backstrand K (2006) Multi-stakeholder partnerships for sustainable development: rethinking legitimacy, accountability and effectiveness. Eur Environ 16(5):290-306

Barilla (2014) Barilla signs sustainable farming project with Italian Tomato Consortium, http://www.barillagroup.com/ corporate/en/home/media/company-news/barilla-signs-sustainable-farming-project-with-italian-tomato-consortium.html

Baskerville RL (1997) Distinguishing action research from participative case studies. J Syst Inf Technol 1(1):24-43

BCFN (2011) New models for sustainable agriculture

BCFN (2015) Good for you, good for the planet. http://www.barillagroup.com/sites/default/files/Barilla_2015_Report_EN_1.pdf

Bernstein H (2014) Food sovereignty via the 'peasant way': a sceptical view. J Peasant Stud 41(6):1031-1063

Blasi E, Monotti C, Ruini L, Landi C, Avolio G, Meriggi P (2015) Eco-innovation as a driver in the agri-food value chain: an empirical study on durum wheat in Italy. J Chain Netw Sci 15(3). https://doi.org/10.3920/JCNS2014.x014ISSN1875-0931

Brouwer H, Woodhill J, Hemmati M, Verhoosel K, van Vugt S (2015) The MSP guide. How to design and facilitate multistakeholder partnerships. Centre for Development and Innovation, Wageningen

Butterfield KD, Reed R, Lemak DJ (2004) An inductive model of collaboration from the stakeholder's perspective. Bus Soc 43(2):162-195

De Schepper S, Dooms M, Haezendonck E (2014) Stakeholder dynamics and responsibilities in public-private partnerships: a mixed experience. Int J Proj Manag 32(7):1210-1222

Dentoni D, Hospes O, Ross RB (2012) Managing wicked problems in agribusiness: the role of multi-stakeholder engagements in value creation. Int Food Agribusiness Manage Rev 15(B):1-12

European Commission, (2018) COM/2018/392 final - 2018/0216 (COD) Proposal for a regulation of the european parliament and of the council establishing rules on support for strategic plans to be drawn up by Member States under the Common agricultural policy (CAP Strategic Plans) and financed by the European Agricultural Guarantee Fund (EAGF) and by the European Agricultural Fund for Rural Development (EAFRD) and repealing Regulation (EU) No 1305/2013 of the European Parliament and of the Council and Regulation (EU) No 1307/2013 of the European Parliament and of the Council

Glasbergen P, Biermann F, Mol AP (eds) (2007) Partnerships, governance and sustainable development: reflections on theory and practice. Cheltenham, UK: Edward Elgar - ISBN 9781847204059 - 315

Hartwich F, Tola J, Engler A, González C, Ghezan G, Vázquez-Alvarado JM, Silva JA, Espinoza JJ, Gottret MV (2008) Building public-private partnerships for agricultural innovation. Food security in practice technical guide series. International food policy research institute, Washington, DC

Heldeweg MA, Sanders M, Harmsen M (2015) Public-private or private-private energy partnerships? Toward good energy governance in regional and local green gas projects. Energy, sustainability and society 5(1):1-12 http://www.barillacfn. com/wpcontent/uploads/2011/12/pp_nuovi_modelli_agricoltura_eng.pdf

Johnsen T, Johnsen RE \& Lamming RC (2008) Supply relationship evaluation: The relationship assessment process (RAP) and beyond. European Management Journal. 26. 274-287.

Johnston J, Gudergan SP (2007) Governance of public-private partnerships: lessons learnt from an Australian case? Int Rev Adm Sci 73(4):569-582

Keast R, Brown K, Mandell M (2007) Getting the right mix: unpacking integration meanings and strategies. Int Pub Manage J 10(1):9-33

Kesavan PC (2015) Shaping science as the prime mover of sustainable agriculture for food and nutrition security in an era of environmental degradation and climate change. Curr Sci 109(3):488-501

Lamming R, Johnsen T, Zheng J, Harland C (2000) An Initial Classification of Supply Networks. International Journal of Operations \& Production Management. 20. 675-691.

Lichtfouse E, Navarrete M, Debaeke P, Souchère V, Alberola C, Menassieu J (2009) Agronomy for sustainable agriculture: a review. In: Sustainable Agriculture. Springer, Netherlands, pp 1-7

Pacheco DF, York JG, Dean TJ, Sarasvathy SD (2010) The coevolution of institutional entrepreneurship: a tale of two theories. J Manag 36(4):974-1010

Pancino B, Pascucci S, Blasi E, Ruini L, Ronchi C (2015) The role of network creation and actor engagement in the adoption and diffusion of sustainable innovations in food value chains, Proceedings of Sidea Congress 2015

Roehrich JK, Lewis MA, George G (2014) Are public-private partnerships a healthy option? A systematic literature review. Soc Sci Med 113:110-119

Ronald P (2011) Plant genetics, sustainable agriculture and global food security. Genetics 188(1):11-20

Rondinelli DA, Berry MA (2000) Environmental citizenship in multinational corporations: social responsibility and sustainable development. Eur Manag J 18(1):70-84

Stewart D, Kennedy A, Pavel A (2014) Beyond nutrition and agriculture policy: collaborating for a food policy. Br J Nutr 112(S2):S65-S74

Waring J, Currie G, Bishop S (2013) A contingent approach to the organization and management of public-private partnerships: an empirical study of English health care. Public Adm Rev 73(2):313-326

Wilhelm MM (2011) Managing coopetition through horizontal supply chain relations: linking dyadic and network levels of analysis. J Oper Manag 29(7):663-676 
Publisher's Note

Springer Nature remains neutral with regard to jurisdictional claims in published maps and institutional affiliations.

Submit your manuscript to a SpringerOpen ${ }^{\odot}$ journal and benefit from:

- Convenient online submission

- Rigorous peer review

- Open access: articles freely available online

- High visibility within the field

- Retaining the copyright to your article

Submit your next manuscript at $\boldsymbol{\nabla}$ springeropen.com 